\title{
Evaluation of the Liver Cancer Prevention of Anthocyanin Extracts from Mulberry (Morus alba L.) Variety PR-01
}

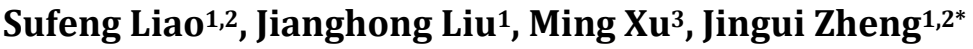 \\ ${ }^{1}$ Institute of Agricultural Product Quality, Fujian Agriculture and Forestry University, Fuzhou, China \\ ${ }^{2}$ Key Laboratory of Ministry of Education for Genetics, Breeding and Multiple Utilization of Crops, College of Crop Science, \\ Fujian Agriculture and Forestry University, Fuzhou, China \\ ${ }^{3}$ Key Laboratory of Fujian Province for Crop Biotechnology, Fujian Agriculture and Forestry University, Fuzhou, China \\ Email: *jinguizheng@126.com
}

How to cite this paper: Liao, S.F., Liu, J.H., Xu, M. and Zheng, J.G. (2018) Evaluation of the Liver Cancer Prevention of Anthocyanin Extracts from Mulberry (Morus alba L.) Variety PR-01. Advances in Bioscience and Biotechnology, 9, 423-442. https://doi.org/10.4236/abb.2018.99030

Received: August 22, 2018

Accepted: September 15, 2018

Published: September 18, 2018

Copyright (c) 2018 by authors and Scientific Research Publishing Inc. This work is licensed under the Creative Commons Attribution International License (CC BY 4.0).

http://creativecommons.org/licenses/by/4.0/

\begin{abstract}
This study aims to evaluate the preventive effects of anthocyanins extracts (MAEs) from mulberry variety PR-01 against $N$-nitrosodiethylamine (NDEA)induced hepatocarcinogenesis in rats. It was found that $150 \mathrm{mg} \cdot \mathrm{kg}^{-1}$ MAEs treatment significantly reduced the NDEA-induced hepatic nodules incidence and hepatocellular carcinoma incidence by $58.30 \%$ and $41.70 \%$ compared to the model group. Meanwhile, MAEs significantly restored the elevated the liver function enzymes, inhibited the tumor necrosis factor alpha and interleukin- 6 levels, elevated the serum interleukin-10 and interferon- $\gamma$ and increased hepatic glutathione-S-transferase and UDP-glucuronosyltransferase 2B1 enzyme activity. Moreover, $150 \mathrm{mg} \cdot \mathrm{kg}^{-1}$ MAEs supplement enhanced glutathione content and the activities of superoxide dismutase, catalase, glutathione peroxidase activities but reduced the malondialdehyde and thiobarbituric acid-reactive substances content by $37.90 \%$ and $44.52 \%$. Furthermore, MAEs pretreatment maintained nuclear factor erythroid 2-related factor 2 (Nrf2), Kelch-like ECH-associated protein 1, heme oxygenase-1, and NAD(P)H: quinine oxidoreductase 1 stimulation and inhibited the expression of TNF- $\alpha$, nuclear factor-kappaB (NF- $\kappa \mathrm{B}$ ), and cyclooxygenase-2 (COX-2), indicating that MAEs exhibit effectively prevention effects against liver cancer via decreased lipid peroxidation, induced Nrf2-mediated antioxidant enzymes and attenuating the inflammatory mediators COX-2 through NF- $\kappa \mathrm{B}$ pathway. Thus, MAEs of mulberry variety PR-01 may be used as a good functional dietary supplement against liver cancer.
\end{abstract}

\section{Keywords}

Mulberry (Morus alba L.) Anthocyanins Extracts, $N$-Nitrosodiethylamine, 
Hepatocarcinogenesis, Antioxidation, Anti-Inflammatory

\section{Introduction}

According to the histological classification, primary liver cancer can be divided into hepatocellular carcinoma (HCC), cholangiocarcinoma and mixed liver cancer, among which HCC is the most common [1] [2]. Despite significant improvements in the clinical diagnosis and treatment of early HCC, the advanced HCC is a highly aggressive tumor with poor or no response to conventional treatment [3] [4]. Therefore, it is urgent to find effective ways or measures to prevent liver cancer.

In the past few decades, dietary studies have shown that regular consumption of fruits and vegetables reduces the risk of chronic diseases such as heart disease and cancer [5] [6] [7]. Colored fruits and vegetable foods contain abundant anthocyanins, including cyanidin-3-glucoside (C3G), pelargonidin-3-glucoside (P3G), malvidin-3-glucoside (M3G), peonidin-3-glucoside, petunidin-3-glucoside, and delphinidin-3-galacside, etc. [8] [9]. Epidemiological and laboratory data have shown that anthocyanins have many biological activities, such as inhibition of the growth of cancerous cells, improving immune responses [7] [10], reducing cardiovascular diseases [11], and promoting anti-obesity effects [12].

Mulberry (Morus alba L.) fruit has been traditionally used in Chinese medicines for its pharmacological effects including antioxidant activity, anti-inflammatory, hepatoprotective effect, and anti-diabetic properties, etc. [13]. Mulberry is rich in anthocyanins (The anthocyanins content was $11.20 \mathrm{mg} \cdot 100 \mathrm{~g}^{-1}-193.00$ $\mathrm{mg} \cdot 100 \mathrm{~g}^{-1}$ in mulberry varieties), among which, the C3G and cyaniding-3-rutinoside (C3R) have been demonstrated to dose-dependently inhibit the migration and invasion of A549 human lung carcinoma cells [14]. Yan et al. [15] showed that mulberry anthocyanin extract ameliorates oxidative damage in HepG2 Cells and prolongs the lifespan of Caenorhabditis elegans through mitogen-activated protein kinase and nuclear factor erythroid 2-related factor 2 (Nrf2) pathways. Li, et al. [10] reported that mulberry anthocyanin has a strong protective effect on the carbon tetrachloride-induced liver fibrosis. Furthermore, it was recently demonstrated that the mulberry extract can increase the protein expression of liver antioxidant, accelerate the metabolism and excretion of nitrophenol, and detoxify the toxicity of nonyl phenol-induced rats [6]. Results of the above studies suggested that mulberry anthocyanins may have potential effects in reducing the risk of cancers by anti-inflammatory, detoxication and chemoprotective properties. However, the anti-cancer activity and the potential anti-cancer mechanisms of mulberry anthocyanins in vivo have not been well elucidated.

In our preliminary work, we have found that black mulberry fruit is abundant in anthocyanins, especially the new cultivars, mulberry variety PR-01, which the 
anthocyanins content is $193.00 \mathrm{mg} \cdot 100 \mathrm{~g}^{-1}, 10.16$-fold that of the common variety $\left(19.00 \mathrm{mg} \cdot 100 \mathrm{~g}^{-1}\right)$ [16]. Therefore, the present study is to determine the mulberry anthocyanin extracts (MAEs) composition of mulberry variety PR-01 fruits and investigate its prevention effects against the $N$-nitrosodiethylamine (NDEA)induced hepatocarcinogenesis in rats and its possible mechanisms.

\section{Materials and Methods}

\subsection{Materials and Chemicals}

Fresh mature mulberry variety PR-01 fruits was obtained in May 2016 from the Institute of Agricultural Product Quality, Fujian Agriculture and Forestry University (Fujian, China) and stored at $-80^{\circ} \mathrm{C}$ on the same day.

All chemicals were ordered from Sigma-Aldrich (Shanghai, China) or Beijing Dingguo Changsheng Biotech Co., Ltd. (Beijing, China). TRIzol reagent, HiScript II Q RT SuperMix for qPCR (+cDNA wiper) and AceQTM qPCR SYBRR Green Master Mix were purchased from Takara Co., Ltd. (Dalian, China). Rabbit polyclonal antibodies nuclear factor-kappaB (NF- $\kappa \mathrm{B})$, cyclooxygenase-2 (COX-2), tumor necrosis factor alpha (TNF- $\alpha$ ), Kelch-like ECH-associated protein 1 (Keap1), NAD(P)H:quinine oxidoreductase1 (NQO1), heme oxygenase-1 (HO-1) and Nrf2 were purchased from Santa Cruz Biotechnology or Cell Signaling (Danvers, MA, US).

\subsection{Preparation of Anthocyanin Rich-Extract of Mulberry}

The PR-01 mulberry anthocyanin rich-extract was extracted as previously described [17]. Freeze mulberry fruits were dried in an ALPHA 1-2LD PLUS lyophilizer (Beijing, China), then ground and sifted for homogenization and stored at $-80^{\circ} \mathrm{C}$. The finedly ground mulberries $(3 \mathrm{~kg}$ ) were extracted with $300 \mathrm{~L}$ of methanol-hydrochloric acid $(999: 1)$ at $37^{\circ} \mathrm{C}$ under the condition of ultrasonic power $200 \mathrm{w}$ and frequency $40 \mathrm{kHz}$ for $30 \mathrm{~min}$. This process was repeated three consecutive times. The extracts is then mixed and evaporated into syrup using RE-2000E rotatory evaporator (Xi'an Taikang Biotechnology Co., Ltd., Xi'an, China). The syrup was dissolved in $1000 \mathrm{~mL}$ of $0.01 \mathrm{~mol} / \mathrm{L} \mathrm{HCl}$, and was defatted with $1200 \mathrm{~mL}$ of ethyl acetate. The water solution was subjected to column chromatography of Amberlite XAD-7 orderly eluted with water and methanol-formic acid (9:1) [18] [19]. The methanol-formic acid elution solution was evaporated into syrup and freeze-dried to yield $403 \mathrm{~g}$ of MAEs. The MAEs stored at $-80^{\circ} \mathrm{C}$ for further use.

\section{3. pH Difference Method Analysis of Total Anthocyanins Content}

Reference to previous study [20], the MAEs was diluted 10-fold with hydrochloric acid-sodium chloride of $\mathrm{pH} 1.0$ and $\mathrm{pH} 4.5$, respectively. The absorbance of MAEs diluents was measured at wavelengths of $520 \mathrm{~nm}$ and $700 \mathrm{~nm}$ by $755 \mathrm{~b}$ UV-Vis spectrophotometer (Xi'an Heb Biotechnology Co., Ltd, Xi'an, China), respectively. The absorbance $(A)$ was calculated by the Equation (1): 


$$
\mathrm{A}=(\mathrm{A} 520 \mathrm{~nm}-\mathrm{A} 700 \mathrm{~nm}) \mathrm{pH} 1.0-(\mathrm{A} 520 \mathrm{~nm}-\mathrm{A} 700 \mathrm{~nm}) \mathrm{pH} 4.5
$$

The total anthocyanin content of MAEs was calculated according to the formula derived by Wrolstad et al. [21]:

$$
\text { Total anthocyanin content }\left(\mathrm{mg} \cdot \mathrm{g}^{-1}\right)=\frac{A \times M W \times D F \times V \times 1000}{\varepsilon \times 1 \times M}
$$

where $M W$ is the molecular weight of cyclamine-3-glucoside (449.2), $D F$ is the dilution, $\varepsilon$ is the molar absorptivity $(29,600), l$ is the optical path $(1.0 \mathrm{~cm}), V$ is the total volume of MAEs diluents $(1.0 \mathrm{ml})$, and $M(0.01 \mathrm{~g})$ is the weight of the MAEs.

\subsection{Electrospray Ionization Mass Spectrometry (ESI-MS) and Ultra-Performance Liquid Chromatography (UPLC) Analysis of Anthocyanins}

Quantifications of anthocyanin monomers were performed on a LC-MS/MS (Thermo Fisher Scientific Inc., SAN JOSE, Calif.) with a MRM mode. The LC-MS analysis was carried out using a LC-MS system comprising of a LC (2010, Finnigan, USA) and LCQ Fleet Ion Trap LC/MS (LCQ Fleet, Thermo Fisher Scientific). Mass spectrum condition: positive ion scanning (ESI ${ }^{+}, \mathrm{m} / \mathrm{z} 200$ $\sim 1200$ ), the collision induced dissociation voltage was $150 \mathrm{~V}$; capillary voltage: $3.8 \mathrm{kV}$; taper hole voltage: $30 \mathrm{v}$. Voltage of photoelectric multiplier: $650 \mathrm{~V}$; Ion source temperature: $120^{\circ} \mathrm{C}$; Take off the solvent temperature: $250^{\circ} \mathrm{C}$.

Separation of anthocyanins in MAEs was on a $2.1 \times 150 \mathrm{~mm}, 1.7 \mu \mathrm{m}$ ACQUITY UPLC BEH C18 column (Waters, UK) analyzed by UPLC using a ACQUITY UPLC H-Class system with a 2996 PDA detector (Waters, Milford, MA, USA). Anthocyanin standards (Sigma-Aldrich, Shanghai, China) were used for quantitative determination.

\subsection{Animals and Experimental Design}

All animal studies were conducted in accordance with Chinese National Guidelines for the Care of Laboratory Animals and approved by the Animal Ethics Committee of the Laboratory Animal Center, Fujian University of Traditional Chinese Medicine (Fujian, China). Four-week-old SPF-grade male Wistar rats were purchased from Shanghai slac laboratory animal Co., Ltd. with animal production license No.: SCXK (HU) 2012-0002. All animals were housed in an SPF barrier system of the Laboratory Animal Center, Fujian University of Traditional Chinese Medicine. Breeding conditions were as follows: temperature $20^{\circ} \mathrm{C}$ $\sim 25^{\circ} \mathrm{C}$, relative humidity $40 \% \sim 60 \%, 12 \mathrm{~h}$ day/night alternation.

Rats were fed with a rodent diet and had tap water ad libitum. After a week of adaptive feeding, the rats were randomly divided into five groups. The control group (Control), model group (NDEA), NDEA + low-dose MAEs (MAEs-75), NDEA + high-dose (MAEs-150), and NDEA + cyanidin-3-glucoside (C3G-150). The animal experiment design is showned in Table 1 . Body weights were measured weekly. Twenty-four hours after the last MAEs administration, the rats were anesthetized by ip of pentobarbital sodium $\left(40 \mathrm{mg} \cdot \mathrm{kg}^{-1}\right)$ for collection of 
Table 1. Sequences of primers used for qRT-PCR analysis.

\begin{tabular}{cccc}
\hline UniProt ID & Gene symbol & Forward primer $\left(5^{\prime}\right.$-3’ $\left.^{\prime}\right)$ & Reverse primer $\left(5^{\prime}-3^{\prime}\right)$ \\
\hline AF304364.1 & Nrf2 & ACCCACCGCCTGGGTTCAGT & TGTGCCCTTGAGCTGGCGAC \\
NM_173295.1 & UGT2b1 & TTAGACCTGGAGCCTGTGGAAA & GCCGAAGATACAAGAACCGTGA \\
NM_017014.1 & GST & AGAGCAGCCGCTACCTCTCAAC & CCAATGTGGACAGGTCCTCCCT \\
NM_001159613.1 & NQO1 & CCAGCAGCCCGGCCAATCTG & AGGTCCGACACGGCGACCTC \\
NM_182864.2 & Keap1 & TGATGGACAAACCCAACTCA & CACTGGACAGGAAACCACCT \\
NM_001004027.1 & HO-1 & AGGCTGAGAATGCCGAGTTC & TGTGGTACAAGGACGCCATC \\
NM_214022.1 & TNF- $\alpha$ & GGAACTGGCAGAGGAGGCGC & CCCCGCCACGAGCAGGAATG \\
NM_199267.2 & NF- $\kappa$ B & TGATGACATACTCCCACAAG & CAATATCCCCAGACCTAAC \\
S67722.1 & COX-2 & ACCAGCAGTTCCAGTATCAGA & AAGTGAGCAAGTCCGTGTTC \\
NM_017008.4 & GAPDH & CGGAGTCAACGGATTTGGTCGTAT & AGCCTTCTCCATGGTGGTGAAGAC \\
\hline
\end{tabular}

blood samples and blood samples were centrifuged at $3000 \mathrm{rpm}$ at $4^{\circ} \mathrm{C}$ for $10 \mathrm{~min}$ to obtain serum. Livers were fully excised from the animal and accurately weighed [6]. The size and number of liver nodules were measured as described earlier [3]. Liver tissue was collected for biochemical and histopathological analyses.

\subsection{Biochemical Assays}

The levels of serum aspartate transaminase (AST), alanine aminotransferase (ALT), $\gamma$-glutamyl transpeptidase (GGT), total bilirubin (TBiL), alkaline phosphatase (ALP), Blood Urea Nitrogen (BUN), and creatinine were detected according to the instructions of commercial kits (Nanjing Jiancheng Bioengineering Engineering Institute, Nanjing, China) using Infinite M200 PRO Varioskan Flash (TECAN, Switzerland). The levels of serum alpha fetal protein (AFP), carcino embryonie antigen (CEA), TNF- $\alpha$, interleukin-6 (IL-6), interleukin-10 (IL-10) and interferon- $\gamma($ IFN- $\gamma$ ) were measured by ELISA kit (CUSABIO Biotech Co., Ltd., Wuhan, China) according to manufacturer's instructions.

Precisely 1 gram of liver was taken, rinsed with cold PBS, pH 7.4, dried with paper wipe, and placed in a $10-\mathrm{mL}$ centrifuge tube. Then the tissue homogenate was centrifuged at $3500 \mathrm{rpm}$ for $15 \mathrm{~min}$. The supernatant was collected in a 10 -mL centrifuge tube (namely $10 \%$ liver homogenate), immediately frozen in liquid nitrogen and stored at $-20^{\circ} \mathrm{C}$ until use [6]. The contents of malondialdehyde (MDA), glutathione (GSH), and the activities of superoxide dismutase (SOD), catalase (CAT), glutathione peroxidase (GSH-Px) were assayed using standard commercially available kits (Nanjing Jiancheng Bioengineering Engineering Institute, Nanjing, China) according to the manufacturer's instructions. The serum thiobarbituric acid-reactive substances (TBARS) concentrations were assayed by rat TBARS ELISA kit (QIYI Biological technology Co., Ltd., Shanghai, China). The levels of Glutathione S-transferase (GST) and UDP-glucuronosyltransferase 2B1 (UGT2b1) in the liver homogenates were measured with ELISA kit (CUSABIO Biotech Co., Ltd., Wuhan, China). 


\subsection{Histological Examination}

Hepatic tissues from each group were washed with cold physiological saline and rapidly excised after the rats were sacrificed. The tissue samples were immediately fixed in $4 \%$ phosphate-buffered paraformaldehyde for $48 \mathrm{~h}$, then dehydrated in a graded ethanol series, cleared in xylene and embedded in paraffin. Sections ( $4 \mu \mathrm{m}$ thick) were stained with hematoxylin and eosin (H\&E) according to published methods [22]. The samples were also sectioned and Masson's trichome staining was performed as previous studies [23]. For histological analysis, the tissue sections were photographed with a microscope (Nikon E200, Nikon Corp., Japan).

\subsection{Immunohistochemical Analysis}

The proteins expression of inflammatory markers in liver tissue was detected by the SABC immunohistochemical method. The main steps are as follows: paraffin section ( $4 \mu \mathrm{m}$ thick) was de-waxed and incubated with sodium citrate buffer ( $\mathrm{pH}$ 6.0 ) at $37^{\circ} \mathrm{C}$ for $5 \mathrm{~min}$ (twice), then washed with $0.1 \mathrm{M}$ PBS for $5 \mathrm{~min}$ ( 3 times), incubated with $3 \%$ hydrogen peroxide at $37^{\circ} \mathrm{C}$ for $10 \mathrm{~min}$, washed with PBS for 5 min (3 times) and placed in a blocking solution at room temperature for $1.5-3$ $h$. The sections were incubated with rabbit polyclonal antibodies, NF- $\kappa \mathrm{B}$, COX-2, and TNF- $\alpha$ (Cell Signaling, Danvers, MA, USA) with TBS and Tween 20 overnight at $4^{\circ} \mathrm{C}$. Then sections were washed with PBS and incubated with HRP-labeled sheep-anti-rabbit secondary antibody at $37^{\circ} \mathrm{C}$ for $1-2 \mathrm{~h}$ followed by streptavidin-biotin-peroxidase at room temperature for $30 \mathrm{~min}$. The slides were washed and the immunoprecipitation was visualized by treating with 3 , 3'-diaminobenzidine for color development for $25 \mathrm{~min}$. Then slides were counterstained with hematoxylin and the brown color signifying the presence of antigen bound to antibody was detected by light microscopy. For the negative control, TBS was used instead of a primary antibody. From ten randomly selected sections of each slide, 500 cells were counted. The percentage of positive cells for each group was calculated using the Image-Pro Plus 6.0 image analysis system.

\subsection{Western Blot Analysis}

Liver tissue was lysated in RIPA lysis buffer containing protease inhibitor cocktail protease inhibitors and phosphatase inhibitors according to the M-PER (R) Mammalian Protein Extraction Reagent (Thermo Scientific, Fair Lawn, NJ, USA). The protein extraction was collected and the concentrations were quantified using a BCA kit (Biotechnology Development Co., Ltd., Beijing, China). The same amount of proteins was separated using 10\% SDS-polyacrylamide gel and transferred to polyvinylidence fluoride (PVDF) membranes. After blocked with $5 \%$ skim milk for $1 \mathrm{~h}$ at room temperature, membranes were incubated with various antibodies against Nrf2 (1:2000), NQO1 (1:1000), HO-1 (1:2000), Keap1 (1:500), NF- $\kappa \mathrm{B}$ (1:4000), COX-2 (1:500), TNF- $\alpha(1: 1000)$, and $\beta$-actin $(1: 2000)$ which purchased from Cell Signaling Technology (Danvers, MA, USA) or Santa 
Cruz Biotechnology (Santa Cruz, CA, USA) overnight at $4^{\circ} \mathrm{C}$. Then membranes were washed and exposed to HRP-conjugated secondary antibodies $(1: 10,000)$ at room temperature for $1 \mathrm{~h}$. Immunoreactive bands were detected by enhanced cheiluminescence solution (CUSABIO Biotech Co., Ltd., Wuhan, China) and exposed to X-ray film using the Bio-Rad Chemi Doc XRS imaging System. The immunoreactive bands were visualized and quantified using Quantity One software and normalized to $\beta$-actin.

\subsection{Real-Time PCR Analysis}

Total RNA was extracted from liver tissue using a TRIzol reagent (Invitrogen, Thermo Fisher Scientific Inc., Beijing, China) according to the manufacturer's instructions. Real-time PCR was performed using the SYBR Green Kit (Takara Biomedical Technology Co., Ltd., Beijing, China) on the ABI Step One RT-PCR system. Primers designed with Primer Premier 5 and Beacon Designer 8.1 was listed in Table 2.

\subsection{Statistical Analysis}

Data was presented by mean standard deviation (SD). Data from study was dealed with SPSS 21.0 statistical package. Statistical analysis was performed by one-way analysis of variance (ANOVA) with Tukey's multiple comparisons or Student's t-test. A P-value of $<0.05$ was considered statistically significant. The GraphPad Prism 6.01 was used for the graphical evaluations.

\section{Results and Discussion}

\subsection{PR-01 Mulberry Anthocyanins Extract Component Analysis}

The total anthocyanins content of the PR-01 mulberry anthocyanins rich-extract was $(718 \pm 8.9) \mathrm{mg} \cdot 100 \mathrm{~g}^{-1}$. UPLC-ESI-MS analysis showed the pelargonidin 3-glucoside (P3G), C3R and C3G is the main anthocyanins (Figure 1), which was in agreement with that reported by Song [17] and Huang [24]. UPLC analysis

Table 2. Experimental design of the study.

\begin{tabular}{|c|c|c|c|}
\hline \multirow[b]{2}{*}{ Groups } & \multirow{2}{*}{$\begin{array}{l}\text { No. of } \\
\text { animals }\end{array}$} & Ip administration & Gavage administration \\
\hline & & $\begin{array}{l}\text { Every Tuesday and Friday 8:30 am } \\
\text { from } 2 \text { weeks to } 12 \text { weeks }\end{array}$ & $\begin{array}{l}\text { Every day } 10: 00 \text { am } \\
\text { from } 1 \text { weeks to } 18 \text { weeks }\end{array}$ \\
\hline Control & 10 & Physiological saline & Distilled water \\
\hline NDEA & 12 & $25 \mathrm{mg} / \mathrm{kg}$ NDEA & Distilled water \\
\hline C3G-150 & 12 & $25 \mathrm{mg} / \mathrm{kg}$ NDEA & $150 \mathrm{mg} / \mathrm{kg} \mathrm{C3G}$ \\
\hline $\begin{array}{l}\text { low-dose MAE } \\
\text { (MAEs-75) }\end{array}$ & 12 & $25 \mathrm{mg} / \mathrm{kg}$ NDEA & $75 \mathrm{mg} / \mathrm{kg}$ MAEs \\
\hline $\begin{array}{l}\text { high-dose MAEs } \\
\text { (MAEs-150) }\end{array}$ & 12 & $25 \mathrm{mg} / \mathrm{kg}$ NDEA & $150 \mathrm{mg} / \mathrm{kg}$ MAEs \\
\hline
\end{tabular}

Ip, intraperitoneal injection; C3G, cyanidin-3-glucoside; MAEs, mulberry anthocyanins extract; NDEA, $N$-nitrosodiethylamine. Gavage doses of MAEs intervention groups were calculated by C3G contents. The MAEs and C3G were dissolved in distilled water. 


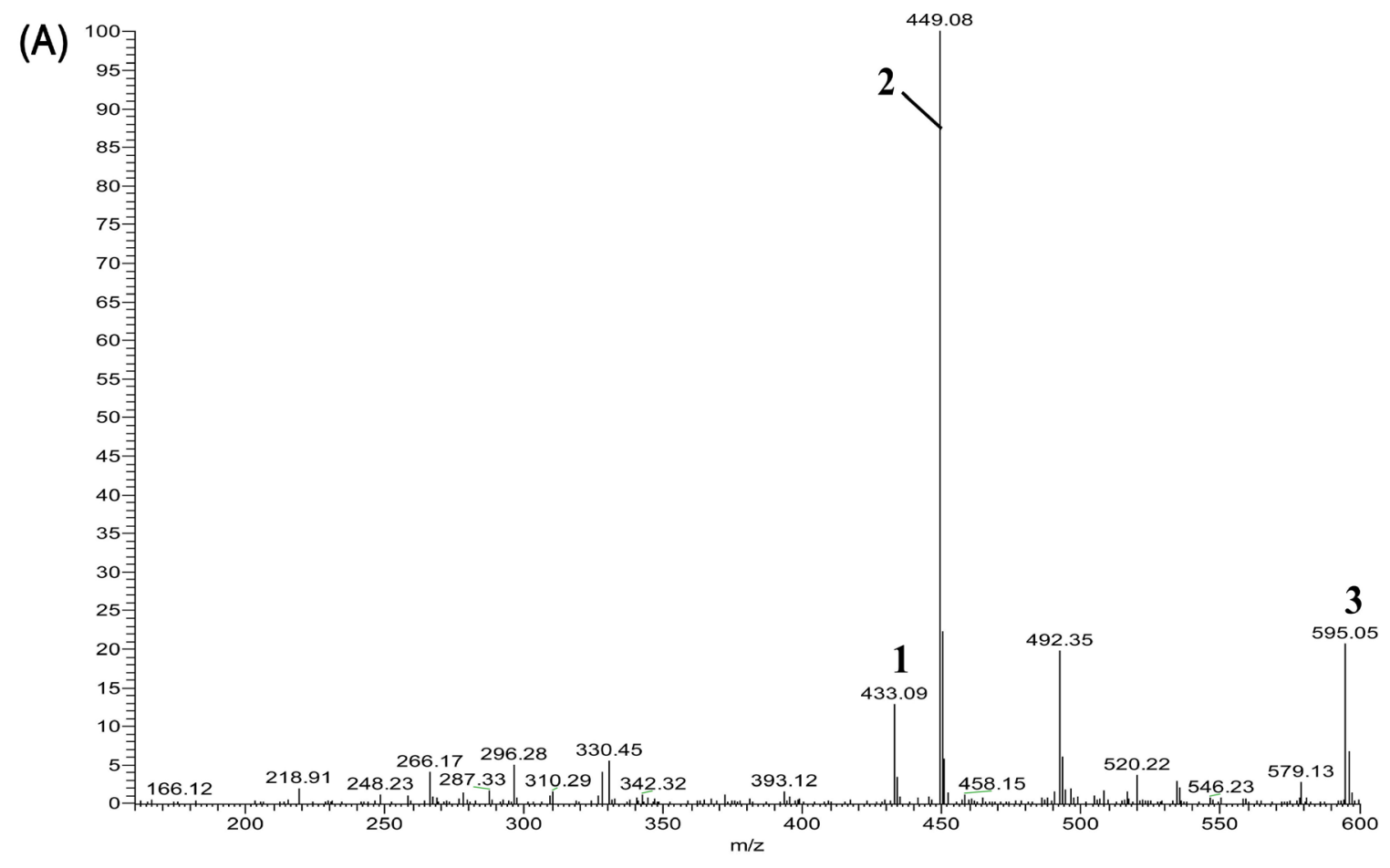

\section{(B) $\mathrm{uAU}$}

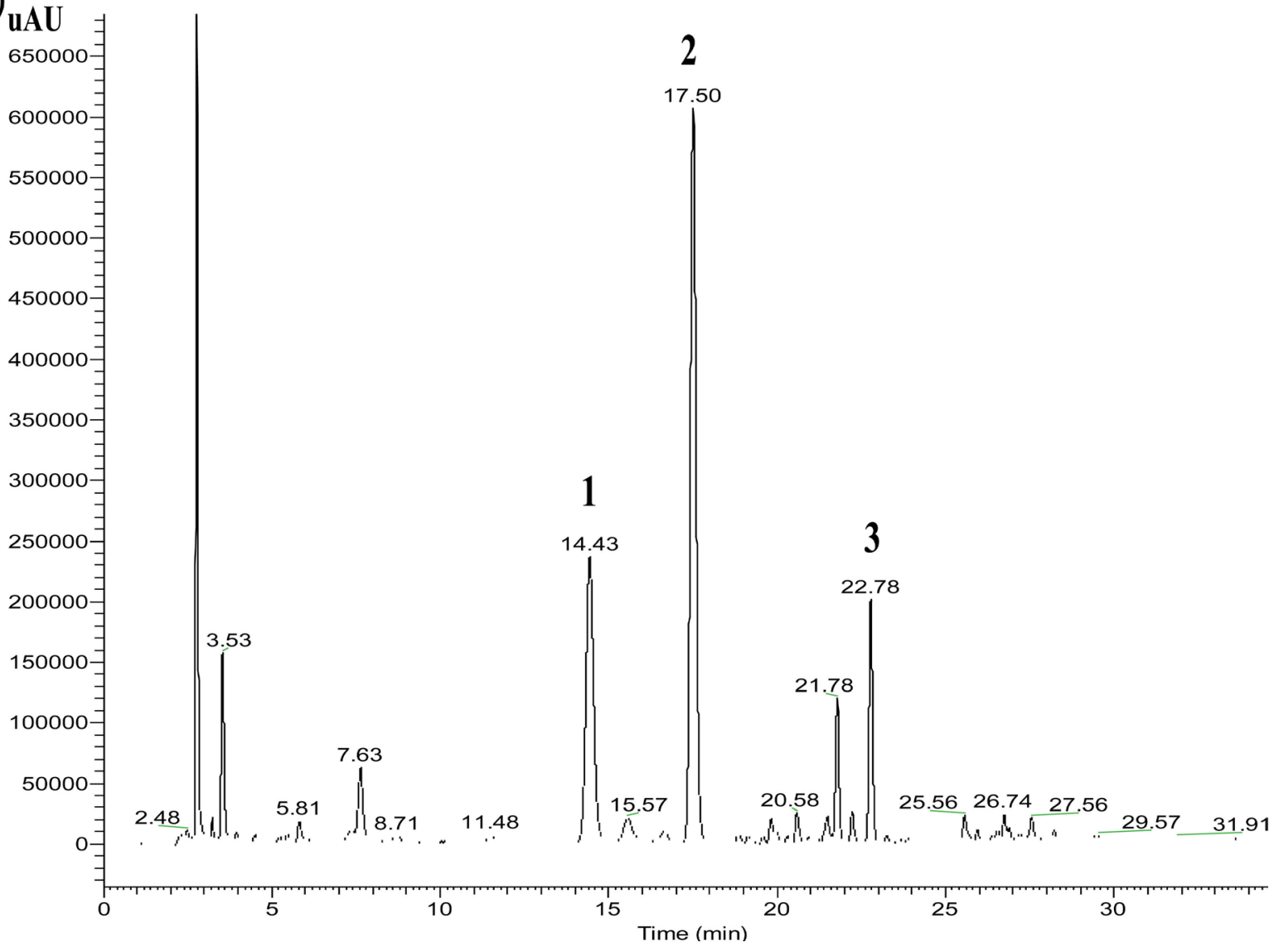

Figure 1. The masss pectrogram and chromatogram of the PR-01 mulberry anthocyanins rich-extract. (A) ESI-MS of MAEs; (B) chromatogram of MAEs. The three peaks correspond to (1) pelargonidin 3-glucoside; (2) C3G; (3) C3R. 
showed that the content of P3G, C3R and C3G in the MAEs is (75.4 \pm 6.5 ) $\mathrm{mg} \cdot \mathrm{g}^{-1},(105.8 \pm 4.1) \mathrm{mg} \cdot \mathrm{g}^{-1}$, and $(593.0 \pm 12.6) \mathrm{mg} \cdot \mathrm{g}^{-1}$, respectively. The mass spectrum of MAEs is shown in Figure 1, while the characterization of chemical constituents of MAEs is presented in Table A1.

\subsection{Alterations in Body Weight, Food Intake, and Liver Index}

As shown in Table 3, the body weight of rats in NDEA group was significantly reduced subsequent to NDEA compared with that in control group $(P<0.01)$, while the weight gains of animals treated with MAEs and C3G-150 were simi$\operatorname{lar}(P>0.05)$. With regard to average daily feed consumption, the NDEA group consumed a lower amount of the feed than the control group $(P<0.01)$. However, after treatment with MAEs and C3G, the daily feed intakes were significantly increased than the NDEA group $(P<0.05)$. Compared to NDEA group, the relative liver weight was remarkably decreased in the MAEs-75 and MAEs-150 groups by $23.64 \%$ and $28.37 \%$, respectively after MAEs treatment $(P<0.01)$.

\subsection{Changes in Liver Function Biomarkers}

NDEA causes liver damage and consequently releases liver enzymes in its selected dose [25]. The past research suggested that mulberry water extracts may serve as liver protective agents [4] [25]. In this study, the elevated activity of ALT, AST, TBiL, ALP, and GGT are indicative of poor hepatic function in the NDEA alone treated animals compared to the control animals (Table 4), as reported by Latief et al. [26]. After treated with MAEs, the levels of the elevated liver function enzymes above mentioned were significantly restored in MAEs-75 and MAEs-150 group animals, suggesting that MAEs has an efficacy function on liver protection. Pretreatment with the higher dose of MAEs $\left(150 \mathrm{mg} \cdot \mathrm{kg}^{-1}\right)$ also reversed the NDEA-induced increase in serum BUN and creatinine to normal levels (Table 4). In addition, the serum CEA and AFP levels were obviously higher in NDEA group than that of the control group $(\mathrm{P}<0.05)$, while 75 $\mathrm{mg} \cdot \mathrm{kg}^{-1}$ MAEs and $150 \mathrm{mg} \cdot \mathrm{kg}^{-1}$ MAEs treatment remarkably reduced the serum CEA and AFP levels by $25.99 \%, 39.32 \%, 32.57 \%$, and $49.24 \%$, respectively compared with the NDEA group (Table 4, $P<0.05$ ). Pretreatment with higher dose of MAEs $\left(150 \mathrm{mg} \cdot \mathrm{kg}^{-1}\right)$ appeared to be more efficient in inhibiting NDEA-induced

Table 3. Effects of MAEs on body weight, feed intake, and liver index in NDEA-induced hepatocarcinogenesis rats.

\begin{tabular}{cccccc}
\hline Groups & Intial Body weight $(\mathrm{g})$ & Final Body weight $(\mathrm{g})$ & Body weight gain $(\mathrm{g})$ & Feed intakes (g/day/rat) & Relative liver weights $^{*}$ \\
\hline Control & $141.25 \pm 4.87^{\mathrm{a}}$ & $592.42 \pm 28.54^{\mathrm{a}}$ & $451.17 \pm 28.98^{\mathrm{a}}$ & $27.06 \pm 3.48^{\mathrm{a}}$ & $2.92 \pm 0.43^{\mathrm{b}}$ \\
NDEA & $141.42 \pm 4.34^{\mathrm{a}}$ & $514.83 \pm 38.32^{\mathrm{c}}$ & $373.42 \pm 38.11^{\mathrm{c}}$ & $21.99 \pm 1.45^{\mathrm{c}}$ & $4.23 \pm 0.64^{\mathrm{a}}$ \\
C3G-150 & $141.92 \pm 7.97^{\mathrm{a}}$ & $531.33 \pm 64.91^{\mathrm{bc}}$ & $389.42 \pm 64.40^{\mathrm{bc}}$ & $24.92 \pm 2.03^{\mathrm{b}}$ & $3.79 \pm 0.62^{\mathrm{a}}$ \\
MAEs-75 & $141.92 \pm 6.52^{\mathrm{a}}$ & $554.42 \pm 42.68^{\mathrm{b}}$ & $413.08 \pm 43.53^{\mathrm{b}}$ & $25.28 \pm 2.34^{\mathrm{ab}}$ & $3.23 \pm 0.49^{\mathrm{b}}$ \\
MAEs-150 & $141.08 \pm 7.47^{\mathrm{a}}$ & $556.00 \pm 21.86^{\mathrm{b}}$ & $414.75 \pm 25.21^{\mathrm{b}}$ & $25.08 \pm 3.50^{\mathrm{ab}}$ & $3.03 \pm 0.38^{\mathrm{b}}$ \\
\hline
\end{tabular}

Note: "Relative liver weights equal liver weight/body weight $\times 100$. Values expressed as mean \pm S.D. $(n=8-10)$. Values with different superscript letters (a, b, c, d, e) within cultivar are significantly different. 
Table 4. Effects of MAEs on serum hepatic enzymes in NDEA-induced hepatocarcinogenesis rats.

\begin{tabular}{|c|c|c|c|c|c|}
\hline Groups & Control & NDEA & C3G-150 & MAEs-75 & MAEs-150 \\
\hline $\operatorname{ALT}(\mathrm{U} / \mathrm{L})$ & $40.70 \pm 8.85^{\mathrm{d}}$ & $85.63 \pm 17.78^{\mathrm{a}}$ & $61.50 \pm 19.63^{\mathrm{b}}$ & $54.80 \pm 11.67^{\mathrm{bc}}$ & $46.10 \pm 11.14^{\mathrm{cd}}$ \\
\hline $\operatorname{AST}(\mathrm{U} / \mathrm{L})$ & $83.10 \pm 12.71^{\mathrm{c}}$ & $173.13 \pm 47.09^{\mathrm{a}}$ & $113.80 \pm 23.70^{\mathrm{b}}$ & $98.10 \pm 21.56^{\mathrm{bc}}$ & $93.20 \pm 13.50^{c}$ \\
\hline $\mathrm{TBiL}$ (mg/dl) & $2.32 \pm 0.26^{c}$ & $4.45 \pm 0.76^{\mathrm{a}}$ & $3.02 \pm 0.41^{\mathrm{b}}$ & $2.89 \pm 0.31^{\mathrm{b}}$ & $2.30 \pm 0.17^{c}$ \\
\hline $\operatorname{ALP}(\mathrm{U} / \mathrm{L})$ & $58.60 \pm 9.16^{\mathrm{b}}$ & $90.63 \pm 14.93^{\mathrm{a}}$ & $78.10 \pm 22.81^{a}$ & $60.20 \pm 17.03^{\mathrm{b}}$ & $53.80 \pm 9.37^{\mathrm{b}}$ \\
\hline GGT (U/L) & $30.26 \pm 3.62^{\mathrm{d}}$ & $115.43 \pm 14.37^{\mathrm{a}}$ & $68.24 \pm 6.08^{c}$ & $50.55 \pm 3.25^{\mathrm{c}}$ & $39.32 \pm 6.54^{\mathrm{cd}}$ \\
\hline $\mathrm{BUN}(\mathrm{mmol} / \mathrm{L})$ & $5.40 \pm 1.07^{\mathrm{b}}$ & $8.87 \pm 1.13^{\mathrm{a}}$ & $7.12 \pm 2.67^{b}$ & $6.02 \pm 2.26^{\mathrm{b}}$ & $5.81 \pm 1.51^{\mathrm{b}}$ \\
\hline Creatinine $(\mu \mathrm{mol} / \mathrm{L})$ & $23.96 \pm 9.58^{e}$ & $68.36 \pm 9.86^{\mathrm{a}}$ & $47.15 \pm 10.54^{\mathrm{bc}}$ & $33.50 \pm 8.85^{\mathrm{de}}$ & $31.43 \pm 14.44^{\mathrm{de}}$ \\
\hline CEA (ng/ml) & $2.16 \pm 0.44^{\mathrm{d}}$ & $7.35 \pm 0.57^{\mathrm{a}}$ & $6.76 \pm 1.18^{\mathrm{ab}}$ & $5.44 \pm 1.85^{\mathrm{bc}}$ & $4.46 \pm 1.87^{\mathrm{c}}$ \\
\hline $\operatorname{AFP}(\mathrm{ng} / \mathrm{ml})$ & $22.27 \pm 6.18^{c}$ & $67.54 \pm 6.91^{\mathrm{a}}$ & $53.47 \pm 16.69^{\mathrm{a}}$ & $45.54 \pm 17.76^{\mathrm{b}}$ & $34.28 \pm 13.2^{\mathrm{bc}}$ \\
\hline
\end{tabular}

Values with different superscript letters (a, b, c, d, e) within cultivar are significantly different.

liver damage in rats.

\subsection{Histopathological Study of Liver Samples}

As one of the most important environmental hepatotoxin and carcinogen, NDEA can cause severe liver damage and lead to severe alterations in the lobular architecture and hampers liver functioning [26]. During the experiment, 2 rats died of severe hepatic tumor pathogenesis at $16^{\text {th }}$ and $18^{\text {th }}$ week in the NDEA group. No death was visible in other group animals. The results of this study shown that low-dose multiple injection of NDEA $\left(25 \mathrm{mg} \cdot \mathrm{kg}^{-1}\right.$ of NDEA twice a week) significantly increased the nodule incidence and the apparent HCC incidence $(100.0 \%, 50.0 \%$, respectively) and only a low mortality rate $(16.7 \%)$ for 18 weeks in the NDEA group, indicating successful induction of liver cancer model. However, there was significant decrease in hepatic nodules incidence, maximum diameter, average number in the MAEs and C3G-150 group rats as compared with NDEA group animals (Table 5, $P<0.05$ ). In particularly, treatment of 150 $\mathrm{mg} \cdot \mathrm{kg}^{-1}$ MAEs prior to C3G showed a significant reduction of the nodule incidence (41.7\%) compared to the NDEA group animals (100\%).

As shown in Table 5, treatment of $150 \mathrm{mg} \cdot \mathrm{kg}^{-1}$ MAEs prior to C3G showed a significant reduction of the apparent HCC incidence (8.3\%) compared to the NDEA group animals (50.0\%). The liver phenotype of rats in the control group was not significantly changed, while the liver size and structure of NDEA group rats were significantly changed (Figure 2). Apparently the liver structure of injured rats was characterized by cells necrosis, hemorrhage, scars and hepatic nodule like structure, abundant eosinophilic cells, basophilic cells and egg cells hyperplasia obviously accompanied by inflammatory cells infiltration [26], which were observed in the liver of NDEA group rats. However, MAEs $\left(75 \mathrm{mg} \cdot \mathrm{kg}^{-1}\right.$ or $150 \mathrm{mg} \cdot \mathrm{kg}^{-1}$ ) and $150 \mathrm{mg} \cdot \mathrm{kg}^{-1} \mathrm{C} 3 \mathrm{G}$ administration regress these changes significantly (Figure 2(B)). The results of masson-stained sections showed that rats developed liver fibrosis after NDEA administration. However, the degree of 
Table 5. Effects of MAEs on hepatic neoplasm-related lesions in NDEA-induced hepatocar-cinogenesis rats.

\begin{tabular}{|c|c|c|c|c|c|c|}
\hline \multicolumn{2}{|c|}{ Hepatic neoplasm-related lesions } & Control & NDEA & C3G-150 & MAEs-75 & MAEs-150 \\
\hline \multirow{3}{*}{ Macroscopic lesions } & Nodule incidence ${ }^{\#}$ & $0(0)$ & $10(100)$ & $8(72.7)$ & $7(58.3)^{*}$ & $5(41.7)^{* *}$ \\
\hline & Max nodule diameter $(\mathrm{mm}){ }^{\boldsymbol{\Lambda}}$ & - & $18.73 \pm 7.13^{\mathrm{a}}$ & $9.42 \pm 5.54^{\mathrm{b}}$ & $4.63 \pm 2.46^{\mathrm{c}}$ & $1.87 \pm 1.79^{\mathrm{c}}$ \\
\hline & Average nodule number ${ }^{\#}$ & ND & $71.33 \pm 62.11^{\mathrm{a}}$ & $48.10 \pm 10.80^{\mathrm{b}}$ & $17.70 \pm 3.42^{\mathrm{d}}$ & $6.13 \pm 5.22^{\mathrm{d}}$ \\
\hline \multirow{4}{*}{ Microscopic lesions } & AHF incidence & $0(0.0)$ & $1(10.0)$ & $2(16.7)$ & $3(25.0)$ & $2(16.7)$ \\
\hline & HA incidence & $0(0.0)$ & $3(30.0)$ & $4(33.3)$ & $3(25.0)$ & $2(16.7)$ \\
\hline & HCC incidence & $0(0.0)$ & $5(50.0)$ & $3(25.0)$ & $2(16.7)^{*}$ & $1(8.3)^{\star *}$ \\
\hline & Total tumor incidence & $0(0.0)$ & $8(80.0)$ & $7(58.3)$ & $5(41.7)$ & $3(25.0)^{*}$ \\
\hline
\end{tabular}

Data are means \pm SDs or $\mathrm{n}(\%)$. Values with different superscript letters (a, b, c, d) within cultivar are significantly different. ${ }^{*} P<0.05$ and ${ }^{* *} P<0.01$ compared with NDEA group by Fisher's exact test. "Visible nodules (diameter $\geq 1 \mathrm{~mm}$ ). ${ }^{\mathbf{\Delta}}$ Max nodule diameter, mean maximum nodule diameter. ND, not detectable; AHF, altered hepatic foci; HA, hepatic adenoma; HCC, hepatocellular carcinoma.

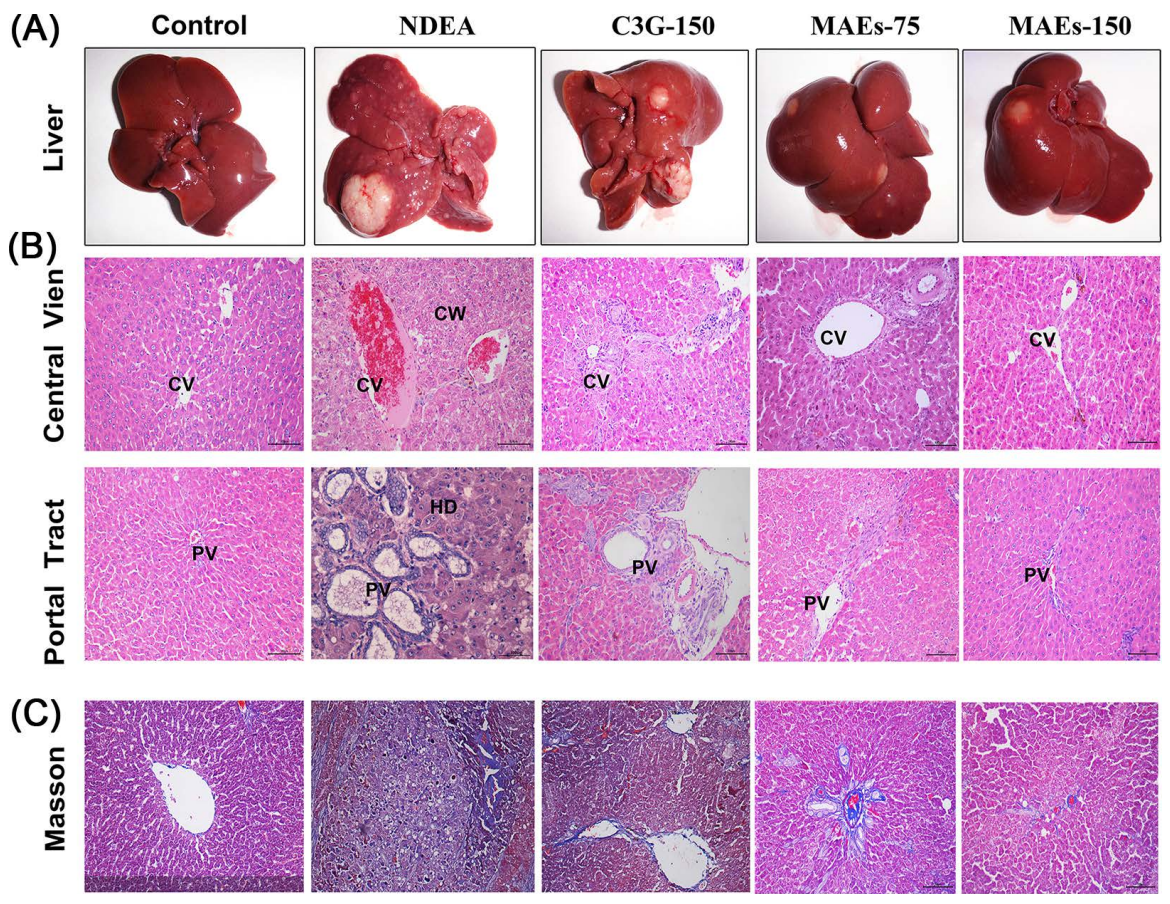

Figure 2. Effects of MAEs on hepatic pathological changes in NDEA-induced hepatocarcinogenesis rats. (A) Liver surface; (B) Liver sections with haematoxylin and esion $(\mathrm{H}$ \& E, 200×). Basophilic cell focus (white arrow) is an altered hepatic focus. At the center of the lobule is the central vein $(\mathrm{CV})$. PV, portal vein. (C) Liver sections with Masson staining $(200 \times)$.

fibrosis in NDEA group animals was more severe compared to rats treated with MAEs or C3G (Figure 2(C)). Cellular vacuolization was also reduced in the MWEs-treated groups (Figure 2(C)).

These results suggested that MAEs is an effective chemopreventive agent for preventing or delaying NDEA-induced hepatocarcinogenesis in rats, among which the high dose of MAEs has the best effect and is superior to C3G. 


\subsection{Antioxidative Effect of MAEs on TBARS and Related Antioxidant Enzymes Activity}

Excess reactive oxygen species produced in the processes of NDEA metabolic activation can interfere with the body's oxidation system, leading to oxidative damage and tissue carcinogenesis, which plays an important role in the pathogenesis of liver cancer [26]. TBARS concentrations were used as markers of oxidative stress [24]. In this study, compared with the control group, the TBARS level of liver tissue in the NDEA group was remarkably increased $(P<0.001)$ 1.88 -fold, which is consistent with earlier reports [13] [27]. Compared with the NDEA group, the hepatic tissue TBARS were significantly reduced in the C3G150, MAEs-75 and MAEs- 150 groups by $39.01 \%, 40.85 \%$, and $44.52 \%$, respectively (Table 6, $P<0.001$ ). Interestingly, these results showed that $150 \mathrm{mg} \cdot \mathrm{kg}^{-1}$ MAEs treatment almost restored the TBARS to the normal level. On this basis, we further detected the effect of MAEs on antioxidant capacity. The activities of antioxidant enzymes, GSH, GSH-Px, CAT and SOD in NDEA group were remarkably lower than that in the control group $(P<0.01)$, while these activities were dramatically promoted by MAEs and C3G $(P<0.05)$. Among which, the $150 \mathrm{mg} \cdot \mathrm{kg}^{-1}$ MAEs treatment rats had the highest levels of antioxidant enzymes in livers. After NDEA treatment, MDA content was obviously elevated in liver of NDEA group rats, which was approximately 2.44 -fold higher than in control group rats $(P<0.01)$, and significantly decreased after MAEs treatment (Table $6, P<0.05)$. Our results showed that NDEA administration changes the antioxidant status, leading to oxidative stress, Whereas MAEs can inhibit lipid peroxidation and enhance antioxidant capacity, so the prevention effect of MAEs against NDEA-induced hepatocarcinogenesis in rats may be closely related to its antioxidant activity. Chen et al. [13] [18] [27] also found that anthocyanins and water extracts from mulberry fruit can scavenge free radicals and shown concentration-dependent antioxidant activity in vitro.

\subsection{Effect of MAEs on Liver GST and UGT2b1}

NDEA's induction increased microsomal phase I metabolizing enzymes with a

Table 6. Effects of MAEs on TBARS and activities of related antioxidant enzymes in livers of NDEA-induced hepatocarcinogenesis rats.

\begin{tabular}{ccccccc}
\hline Groups & TBARS (nmol/mg protein) & GSH $(\mathrm{mg} / \mathrm{g})$ & GSH-Px $(\mathrm{U} / \mathrm{mg})$ & SOD $(\mathrm{U} / \mathrm{mg})$ & CAT $(\mathrm{U} / \mathrm{mg})$ & $\mathrm{MDA}(\mathrm{nmol} / \mathrm{mg})$ \\
\hline Control & $241.67 \pm 11.61^{\mathrm{c}}$ & $4.38 \pm 0.71^{\mathrm{a}}$ & $387.53 \pm 23.72^{\mathrm{a}}$ & $172.09 \pm 14.28^{\mathrm{a}}$ & $35.89 \pm 8.58^{\mathrm{a}}$ & $4.73 \pm 1.07^{\mathrm{c}}$ \\
NDEA & $454.74 \pm 25.4^{\mathrm{a}}$ & $1.23 \pm 0.34^{\mathrm{e}}$ & $293.02 \pm 53.17^{\mathrm{b}}$ & $94.56 \pm 20.70^{\mathrm{c}}$ & $14.56 \pm 3.10^{\mathrm{d}}$ & $11.55 \pm 3.66^{\mathrm{a}}$ \\
C3G-150 & $277.36 \pm 30.24^{\mathrm{b}}$ & $1.94 \pm 1.03^{\mathrm{d}}$ & $363.57 \pm 28.85^{\mathrm{a}}$ & $127.47 \pm 24.65^{\mathrm{b}}$ & $23.26 \pm 5.35^{\mathrm{c}}$ & $8.47 \pm 2.18^{\mathrm{b}}$ \\
MAEs-75 & $268.96 \pm 32.90^{\mathrm{bc}}$ & $2.85 \pm 0.70^{\mathrm{c}}$ & $364.78 \pm 32.04^{\mathrm{a}}$ & $147.45 \pm 36.13^{\mathrm{b}}$ & $28.21 \pm 7.27^{\mathrm{bc}}$ & $5.95 \pm 2.33^{\mathrm{c}}$ \\
MAEs-150 & $252.30 \pm 23.09^{\mathrm{bc}}$ & $3.61 \pm 0.25^{\mathrm{b}}$ & $380.94 \pm 37.81^{\mathrm{a}}$ & $170.77 \pm 18.34^{\mathrm{a}}$ & $32.30 \pm 5.55^{\mathrm{ab}}$ & $5.30 \pm 1.00^{\mathrm{c}}$ \\
\hline
\end{tabular}

The data are the mean \pm SD from 8 samples for each group and at least three independent measurements. Values with different superscript letters ( $\mathrm{a}$, b, $\mathrm{c}$, $\mathrm{d}$ ) within cultivar are significantly different. TBARS, thiobarbituric acid-reactive substances; GSH, Glutathione; GSH-Px, glutathione peroxidase; SOD, superoxide dismutase; CAT, catalase; MDA, malondialdehyde. 
simultaneous decrease in the Phase II detoxifying enzyme [6] [28]. GST and UGT2b1 play an important role in the detoxification and excretion of toxins, carcinogens, which may actively modulated by Nrf2 and the antioxidant response element [29]. In this study, administration of NDEA, the significant reduction in UGT2b1 and GST activity in livers of NDEA group were observed (Figure $1(\mathrm{~A}), P<0.05)$. Whereas the levels of GST and UGT2b1 in livers of MAEs-75 and MAEs-150 group rats were remarkably increased as compared to the NDEA group. What's more, the hepatic GST and UGT2b1 levels of MAEs-150 group were obviously higher than that of C3G-150 group $(P<0.05)$, and closed to the normal level. The result of the qRT-PCR also showed that NDEA induced GST and UGT2b1 mRNA expressions and MAEs repressed these alterations (Figure 3(B)). These results suggested MAEs can inhibit tumor development by stimulating the activity of phase II detoxification enzyme.

\subsection{MAEs Activated the Nrf2 Signaling Pathway and Its Downstream Detoxification Enzymes}

Nrf2-mediated antioxidant, detoxification enzymes and anti-inflammatory signaling are through Nrf2-ARE pathways to protect organisms against cellular damage caused by oxidative stress [28]. Yan et al. [15] reported that consumption of mulberry anthocyanin extract maintained Nrf2, HO-1, and p38 MAPK stimulation that were involved in oxidative stress modulation. The results of this study shown that Nrf2 activation in livers of rats was induced by $150 \mathrm{mg} \cdot \mathrm{kg}^{-1}$ MAEs, accompanied by the stimulation the mRNA expressions of NQO-1, Keap1, and HO-1 (Figure 3(B), $P<0.05$ ). Similar findings were observed in the measurements of Nrf2, Keap1, HO-1, and NQO-1 protein levels. Compared with the control and NDEA groups, treatment of $150 \mathrm{mg} \cdot \mathrm{kg}^{-1}$ MAEs caused significant changes in the protein expressions of Nrf2, Keap1, HO-1, and NQO-1 in the MAEs-150 group $(P<0.05)$, but less obvious changes were found in MAEs-75 group (Figure $3(C)$ ). Combining these results, it was concluded that MAEs may activate the Nrf2 signaling pathway and induce Nrf2-mediated antioxidant enzymes, further activate the expression of downstream phase II detoxifying GST and UGT2b1, which then accelerated the elimination of the metabolites of NDEA, thereby achieving the goal of detoxification.

\subsection{MAEs Attenuated the NDEA-Induced Inflammatory Response}

Studies showed that the main cause of NDEA-induced liver cancer is inducing chronic inflammatory response and abnormal repair after liver injury [30] [31]. Hassimotto et al. studies showed that administration of wild mulberry extract suppressed carrageenan-induced acute inflammation [7]. As shown in Fig 3A, relative to the NDEA group (85.26 pg.mL $\left.\mathrm{mL}^{-1}, 97.60 \mathrm{pg} \cdot \mathrm{mL}^{-1}\right)$, the IL- 6 and TNF- $\alpha$ levels were remarkably inhibited by MAEs-75 (46.24 $\mathrm{pg} \cdot \mathrm{mL}^{-1}, 50.08 \mathrm{pg} \cdot \mathrm{mL}^{-1}$ ), MAEs-150 (37.93 pg. $\left.\mathrm{mL}^{-1}, 36.75 \mathrm{pg} \cdot \mathrm{mL}^{-1}\right)$, and C3G-150 (62.14 pg. $\mathrm{mL}^{-1}, 56.62$ $\left.\mathrm{pg} \cdot \mathrm{mL}^{-1}\right)$. The inhibition of IL- 6 and TNF- $\alpha$ showed a dose-dependent relationship with MAEs $\left(75 \mathrm{mg} \cdot \mathrm{kg}^{-1}\right.$ and $\left.150 \mathrm{mg} \cdot \mathrm{kg}^{-1}\right)$. Besides, MAEs treatments 

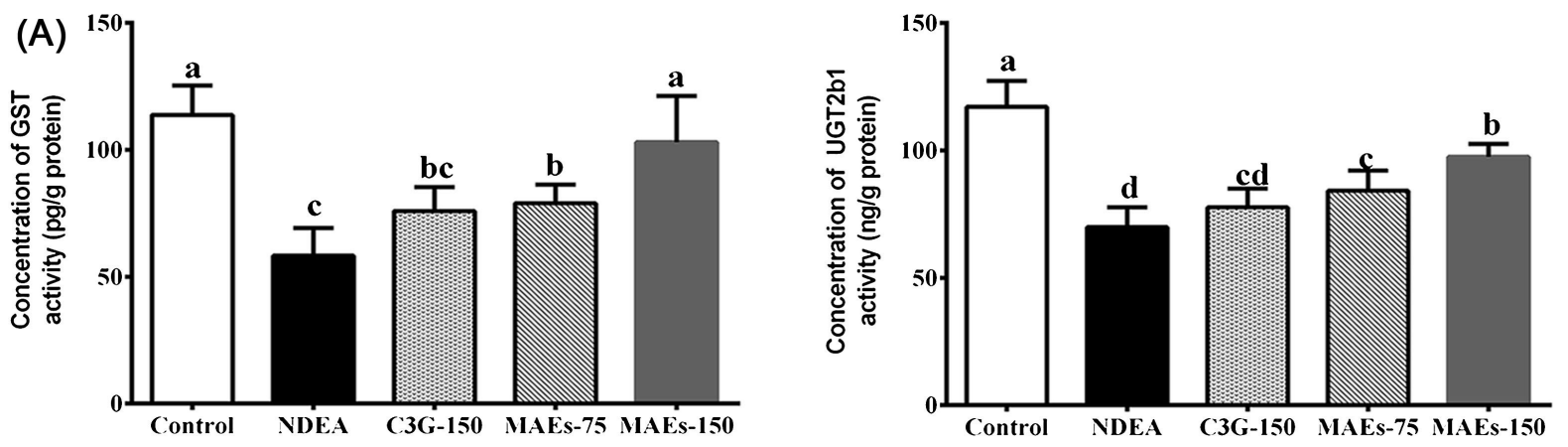

(B)
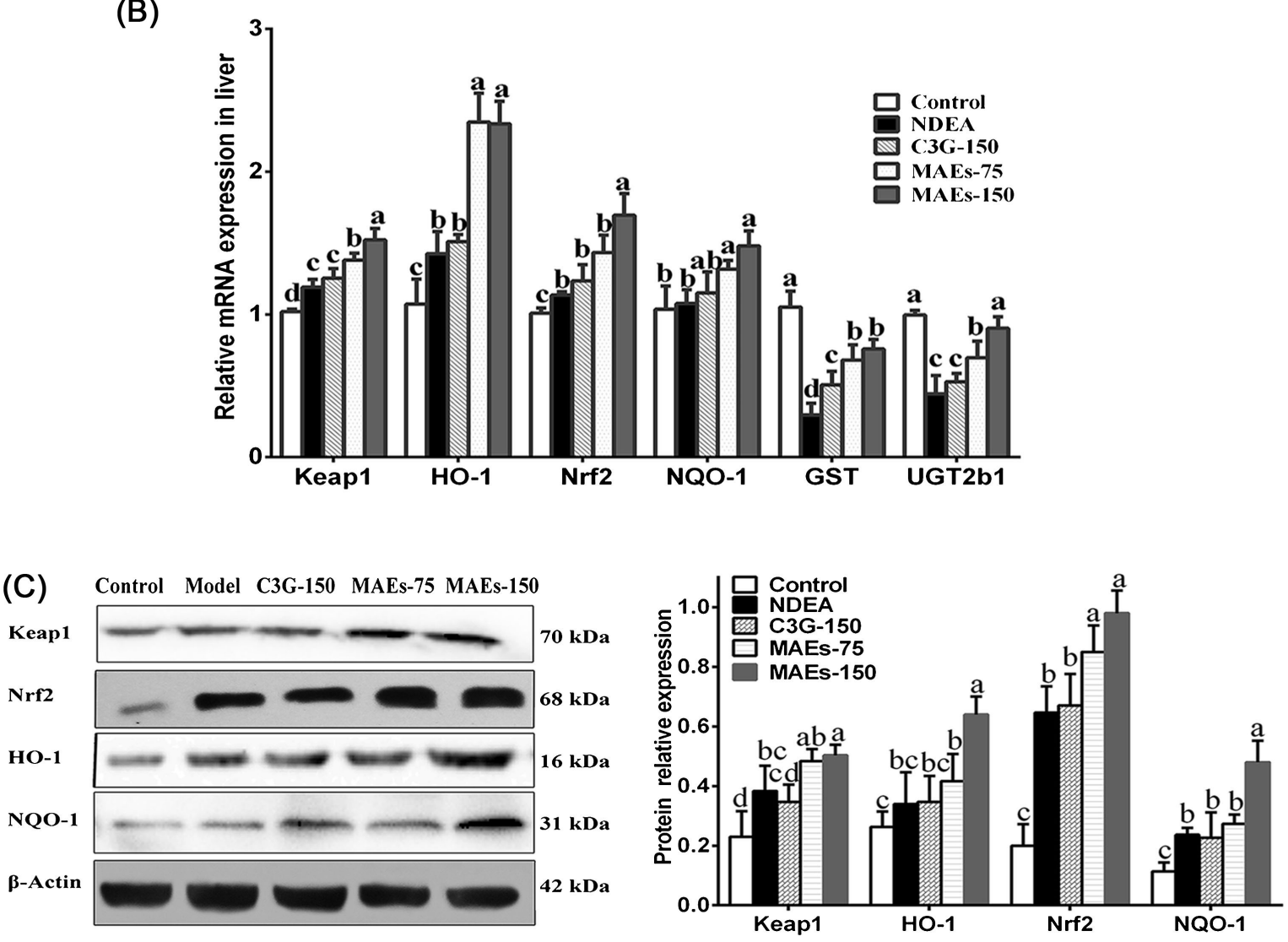

Figure 3. Effects of MAEs on the expression of Nrf2 and its downstream detoxification enzymes. (A) Effects of MAEs on GST and UGT2b1 levels in liver microsomes of rats exposed to NDEA. Values are expressed as concentration of the hepatic microsomal GST and UGT2b1 activity. GST, glutathione-S-transferase; UGT2b1, UDP glucuronosyl-transferase UGT2b1. (B) The mRNA relative expression levels of GST, UGT2b1, Keap1, HO-1, Nrf2, and NQO-1 in control and treatment groups. GAPDH was used as an internal control. (C) The representative immunoblots and protein levels of Keap1, HO-1, Nrf2, and NQO-1 in liver tissues in the rats of each group. Values with different superscript letters (a, b, c, d) within cultivar are significantly different among groups $(P<0.05)$.

increased anti-inflammatory cytokines IL-10 and IFN- $\gamma$ in serum after NDEA treatment (Figure $4(\mathrm{~A})$ ).

NF- $\kappa$ B, TNF- $\alpha$, and COX-2 plays an important role in the development of inflammation [13] [24]. Thus, we further determined whether MAEs can reverse the effects on inflammation-related gene (TNF- $\alpha$, NF- $\kappa$ B, and COX-2) expression by qRT-PCR and Western blot. The result of qRT-PCR analysis revealed 
(A)
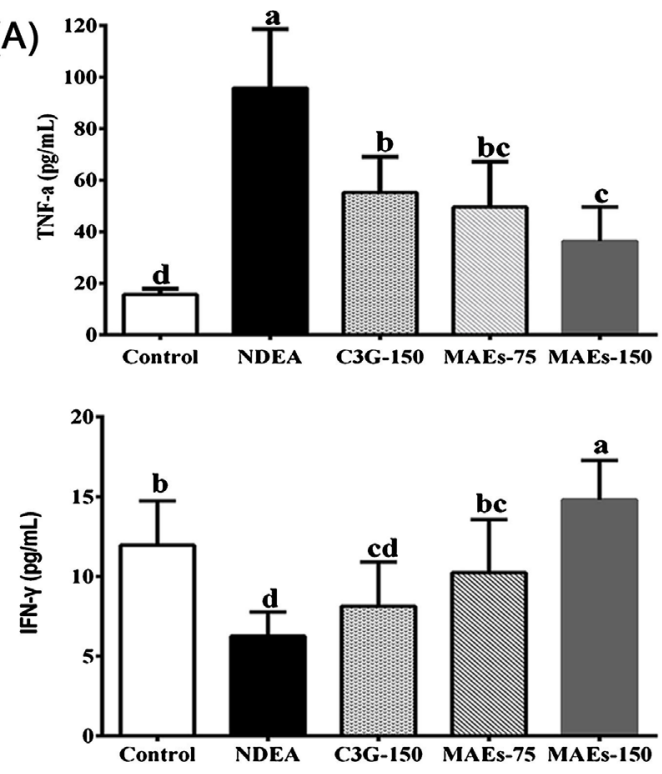
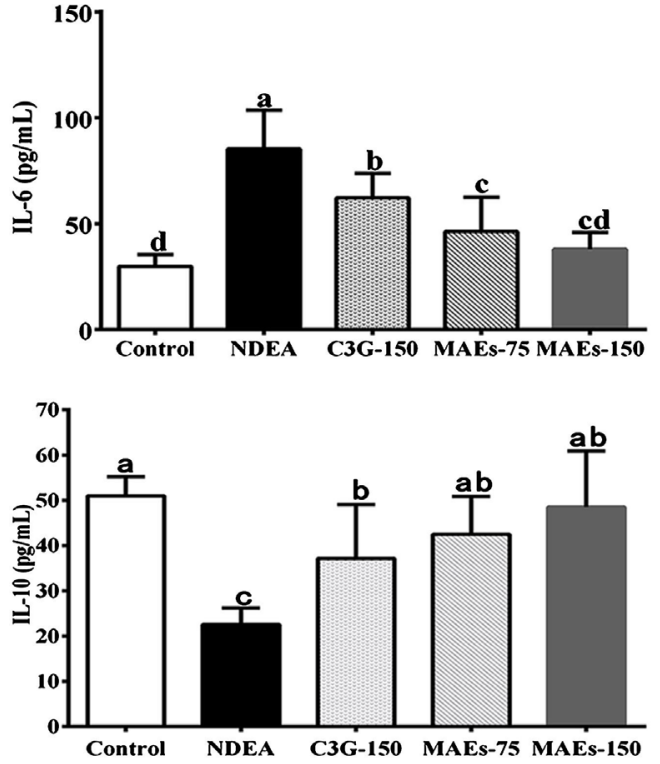

(B)

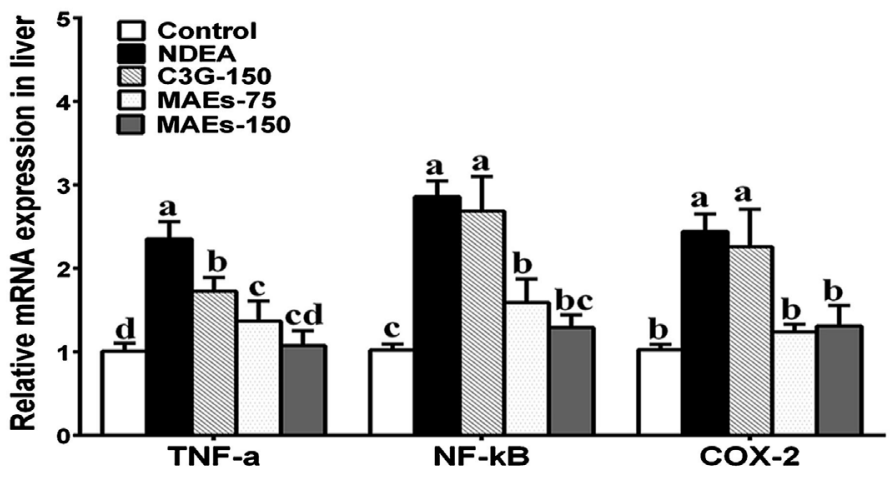

(C)
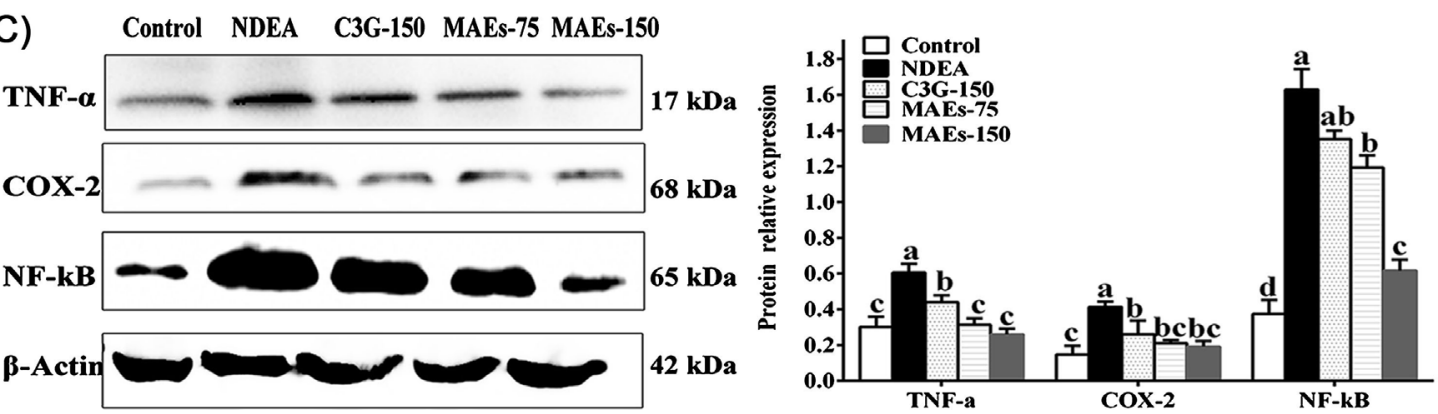

Figure 4. Effects of MAEs on markers of inflammation in NDEA-induced hepato-carcinogenesis rats. (A) The markers of pro-and anti-inflammatory cytokines in serum of each group rats. (B) The mRNA expression of TNF- $\alpha$, NF- $\kappa$ B, and COX-2 in livers of each group rats. GAPDH was used as an internal control; (C) Representative immunoblots of TNF- $\alpha$, NF- $\kappa \mathrm{B}$, and COX- 2 and its protein levels in livers of each group rats. $\beta$-actin was used as an internal control. Values expressed as mean \pm SD. Values with different superscript letters $(a, b, c, d)$ within cultivar are significantly different.

that, MAEs obviously decreased the TNF- $\alpha$, NF- $\kappa$ B, and COX- 2 mRNA expression in the livers of MAEs-75 and MAEs-150 group rats, all of which were remarkably higher than that of $\mathrm{C} 3 \mathrm{G}$ treatment rats (Figure $4(\mathrm{~B})$ ). These results indicate that MAEs reduced NDEA-induced TNF- $\alpha$, NF- $\kappa \mathrm{B}$, and COX-2 mRNA 
expression in a dose-dependent manner. Similar findings were observed in the measurements of the TNF- $\alpha$, NF- $\kappa \mathrm{B}$, and COX-2 protein levels. Treatment with NDEA improved the protein expression levels of TNF- $\alpha, \mathrm{NF}-\kappa \mathrm{B}$, and COX-2 by 2.01-, 4.35-, and 2.81-fold in NDEA group when compared with the control group, respectively (Figure $4(C)$ ). However, administration of MAEs significantly reduced the levels of TNF- $\alpha, \mathrm{NF}-\kappa \mathrm{B}$, and COX-2 proteins in MAEs-75 and MAEs-150 group rats (Figure $4(C), P<0.05$ ). Moreover, immunohistochemistry of NDEA-treated liver sections exhibited TNF- $\alpha, \mathrm{NF}-\kappa \mathrm{B}$, and COX-2 positive cells in NDEA group. The amount of TNF- $\alpha, \mathrm{NF}-\kappa \mathrm{B}$, and COX-2 positive cells in the liver, which was approximately 6.16-, 4.53-, and 15.92-fold higher in NDEA group rats than in control group rats $(P<0.001)$, reduced remarkably after MAEs (75 and $150 \mathrm{mg} \cdot \mathrm{kg}^{-1}$ ) treatment (Figure 5, $P<0.01$ ).

The present study indicated that the NDEA-induced liver cancer may be related to the inflammatory reaction in rats, and MAEs may exert anti-inflammation by regulating the levels of inflammatory cytokines and attenuating the inflammatory

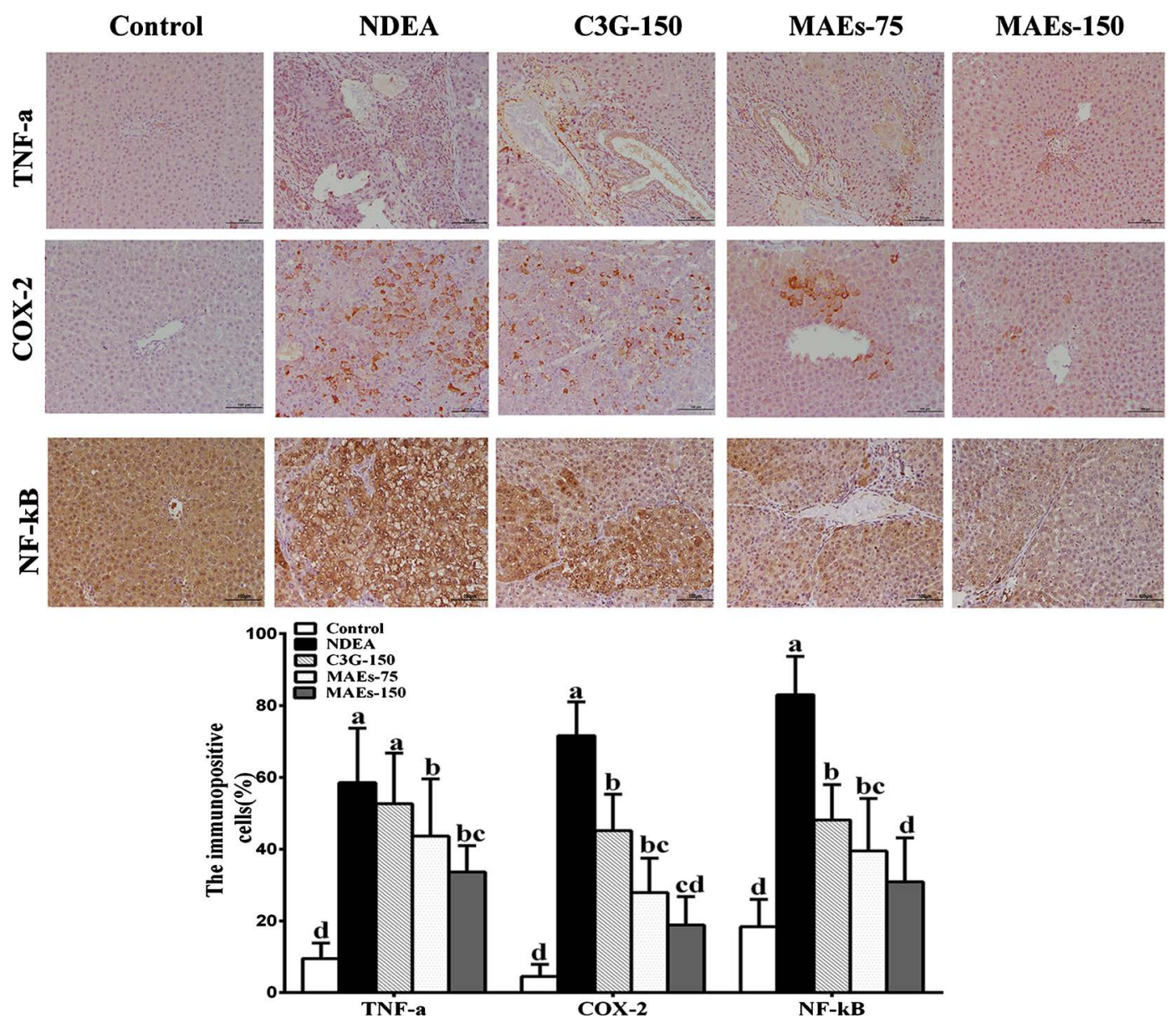

Figure 5. Representative immunohistochemical staining of TNF- $\alpha$, COX-2, and NF- $\kappa$ B in the liver of control and experimental animals at $\times 200$ original magnification. Bar graph represents average percentage of positive stained cells of TNF- $\alpha$, COX-2, and NF- $\kappa$ B in the liver of control and experimental groups. Results are expressed as mean \pm SD. Values with different superscript letters ( $a, b, c, d)$ within cultivar are significantly different. 
mediators COX-2 through NF- $\kappa$ B inhibition pathway.

\section{Conclusion}

In vivo studies, we present evidence that MAEs of mulberry variety PR-01 fruits exhibit prevention of NDEA-induced liver damage, fibrosis and hepatocellular carcinoma via reducing liver function enzymes, decreasing lipid peroxidation, promoting antioxidant enzymes, and increasing the hepatic phase II detoxifying enzymes GST and UGT2b1 activity as well as inhibiting the inflammatory responses by blocking NF- $\kappa \mathrm{B}$ activation and the release of pro-inflammatory mediators. These findings provided that a promising usefulness for MAEs in the prevention of the liver cancer.

\section{Acknowledgements}

This study was supported by the National Key Research and Development Program of China (2017YFD0100100), the National Key Technology R\&D Program of China (2013BAD01B05), the National Natural Science Foundation of China (30600415), the Science and Technology Innovation Platform Development Program of Fujian Agriculture and Forestry University of China (PTJH13001, PTJH12015), and the Science and Technology Innovation Fund of Fujian Agriculture and Forestry University of China (CXZX2017245).

\section{Author Contributions}

JG Zheng and SF Liao conceived and designed the experiments. SF Liao and JH Liu performed the experiments, analyzed the data. SF Liao drafted the manuscript. JG Zheng and $\mathrm{M} \mathrm{Xu}$ revised the manuscript.

\section{Conflicts of Interest}

There is no conflict of interest in this article. All the authors reviewed the paper and approved the final version.

\section{References}

[1] World Health Organization (2014) Liver Cancer: Estimated Incidence, Mortality and Prevalence Worldwide in 2012.

http://globocan.iarc.fr/Pages/fact_sheets_cancer.aspx

[2] Cancer Research Fund/American Institute for Cancer Research (2018) Diet, Nutrition, Physical Activity, and Liver Cancer. Continuous Update Project Export.

https://www.wcrf.org/dietandcancer

[3] Chen, Y.J., Wallig, M.A. and Jeffery, E.H. (2016) Dietary Broccoli Lessens Development of Fatty Liver and Liver Cancer in Mice Given Diethylnitrosamine and Fed a Western or Control Diet. Journal of Nutrition, 146, 542-550. https://doi.org/10.3945/jn.115.228148

[4] Huang, H.P., Ou, T.T. and Wang, C.J. (2013) Mulberry (Sang Shen Zi) and Its Bioactive Compounds, the Chemoprevention Effects and Molecular Mechanisms in Vitro and in Vivo. Journal of Traditional and Complementary Medicine, 3, 7-15. 
https://doi.org/10.4103/2225-4110.106535

[5] Herr, I. and Buchler, M.W. (2010) Dietary Constituents of Broccoli and Other Cruciferous Vegetables: Implications for Prevention and Therapy of Cancer. Cancer Treatment Reviews, 36, 377-383. https://doi.org/10.1016/j.ctrv.2010.01.002

[6] Liu, H., Yang, J., Huang, S.W., Liu, R.J., He, Y.J., Zheng, D.D. and Liu, C.H. (2017) Mulberry Crude Extracts Induce Nrf2 Activation and Expression of Detoxifying Enzymes in Rat Liver: Implication for Its Protection against NP-Induced Toxic Effects. Journal of Functional Foods, 32, 367-374.

https://doi.org/10.1016/j.jff.2017.03.024

[7] Hassimotto, N.M., Moreira, V., do Nascimento, N.G., Souto, P.C., Teixeira, C. and Lajolo, F.M. (2013) Inhibition of Carrageenan-Induced Acute Inflammation in Mice by Oral Administration of Anthocyanin Mixture from Wild Mulberry and Cyanidin-3-Glucoside. BioMed Research International, 146716-146710.

[8] Gopalakrishnan, R., Sundaram, J., Sattu, K., Pandi, A. and Thiruvengadam, D. (2013) Dietary Supplementation of Silymarin Is Associated with Decreased Cell Proliferation, Increased Apoptosis, and Activation of Detoxification System in Hepatocellular Carcinoma. Molecular and Cellular Biochemistry, 377, 163-176. https://doi.org/10.1007/s11010-013-1582-1

[9] Khoo, H.E., Azlan, A., Tang, S.T. and Lim, S.M. (2017) Anthocyanidins and Anthocyanins: Colored Pigments as Food, Pharmaceutical Ingredients, and the Potential Health Benefits. Food \& Nutrition Research, 61, 1361779.

https://doi.org/10.1080/16546628.2017.1361779

[10] Li, L., Wang, L., Wu, Z., Yao, L., Wu, Y., Huang, L., Liu, K., Zhou, X. and Gou, D. (2014) Anthocyanin-Rich Fractions from Red Raspberries Attenuate Inflammation in Both RAW264.7 Macrophages and a Mouse Model of Colitis. Scientific Reports, 4, 6234. https://doi.org/10.1038/srep06234

[11] Reis, J.F., Monteiro, V.V., de Souza Gomes, R., do Carmo, M.M., da Costa, G.V., Ribera, P.C. and Monteiro, M.C. (2016) Action Mechanism and Cardiovascular Effect of Anthocyanins: A Systematic Review of Animal and Human Studies. Journal of Translational Medicine, 14, 315. https://doi.org/10.1186/s12967-016-1076-5

[12] Azzini, E., Giacometti, J. and Russo, G.L. (2017) Antiobesity Effects of Anthocyanins in Preclinical and Clinical Studies. Oxidative Medicine and Cellular Longevity, 2740364-2740374. https://doi.org/10.1155/2017/2740364

[13] Kujawska, M., Ewertowska, M., Adamska, T. and Sadowski, C. (2014) Antioxidant Effect of Lycopene-Enriched Tomato Paste on N-Nitrosodiethylamine-Induced Oxidative Stress in Rats. Journal of Physiology and Biochemistry, 70, 981-990. https://doi.org/10.1007/s13105-014-0367-7

[14] Asgharpour, A., Cazanave, S.C., Pacana, T., Seneshaw, M., Seneshaw, M., Vincent, R., Banini, B.A., Kumar, D.P., Daita, K., Min, H.K., Mirshahi, F., Bedossa, P., Sun, X., Hoshida, Y., Koduru, S.V., Contaifer, D.J, Warncke, U.O., Wijesinghe, D.S. and Sanyal, A.J. (2016) A Diet-Induced Animal Model of Non-Alcoholic Fatty Liver Disease and Hepatocellular Cancer. Journal of Hepatology, 65, 579-588.

https://doi.org/10.1016/j.jhep.2016.05.005

[15] Yan, F., Chen, Y., Azat, R. and Zheng, X. (2017) Mulberry Anthocyanin Extract Ameliorates Oxidative Damage in HepG2 Cells and Prolongs the Lifespan of Caenorhabditis elegans through MAPK and Nrf2 Pathways. Oxidative Medicine and Cellular Longevity, 7956158-7956170.

[16] Cheng, Z.X., Xu, M., Yang, Z.J., Chen, X.W. and Zheng, J.G. (2016) A Preliminary Report of Excellent Crop Germplasm with Rich Functional Ingredients. Fujian 
Agricultural Science and Technology, 7, 83-84.

[17] Zou, T.B., Wang, M., Gan, R.Y. and Ling, W.H. (2011) Optimization of Ultrasound-Assisted Extraction of Anthocyanins from Mulberry, Using Response Surface Methodology. International Journal of Molecular Sciences, 12, 3006-3017. https://doi.org/10.3390/ijms12053006

[18] Du, Q., Zheng, J. and Xu, Y. (2008) Composition of Anthocyanins in Mulberry and Their Antioxidant Activity. Journal of Food Composition and Analysis, 21, 390-395. https://doi.org/10.1016/j.jfca.2008.02.007

[19] Huang, H.P., Chang, Y.C., Wu, C.H., Hung, C.N. and Wang, C.J. (2011) Anthocyanin-Rich Mulberry Extract Inhibit the Gastric Cancer Cell Growth in Vitro and Xenograft Mice by Inducing Signals of p38/p53 and c-Jun. Food Chemistry, 129, 1703-1709. https://doi.org/10.1016/j.foodchem.2011.06.035

[20] Chen, S.S., Zhang, F.F., Ning, J.F., Liu, X., Zhang, Z.W. and Yang, S.Q. (2015) Predicting the Anthocyanin Content of Wine Grapes by NIR Hyperspectral Imaging. Food Chemistry, 172, 788-793. https://doi.org/10.1016/j.foodchem.2014.09.119

[21] Wrolstad, R.E., Durst, R.W. and Lee, J. (2005) Tracking Color and Pigment Changes in Anthocyanin Products. Trends in Food Science \& Technology, 16, 423-428. https://doi.org/10.1016/j.tifs.2005.03.019

[22] Sarikaphuti, A., Nararatwanchai, T., Hashiguchi, T., Ito, T., Thaworanunta, S., Kikuchi, K., Oyama, Y., Maruyama, I. and Tancharoen, S. (2013) Preventive Effects of Morus alba L. Anthocyanins on Diabetes in Zucker Diabetic Fatty Rats. Experimental and Therapeutic Medicine, 6, 689-695.

https://doi.org/10.3892/etm.2013.1203

[23] Jiang, W., Gao, M., Sun, S., Bi, A., Xin, Y., Han, X., Wang, L., Yin, Z. and Luo, L. (2012) Protective Effect of L-Theanine on Carbon Tetrachloride-Induced Acute Liver Injury in Mice. Biochemical and Biophysical Research Communications, 422, 344-350. https://doi.org/10.1016/j.bbrc.2012.05.022

[24] Tang, C.C., Huang, H.P., Lee, Y.J., Tang, Y.H. and Wang, C.J. (2013) Hepatoprotective Effect of Mulberry Water Extracts on Ethanol-Induced Liver Injury via Anti-Inflammation and Inhibition of Lipogenesis in C57BL/6J Mice. Food and Chemical Toxicology, 62, 786-796. https://doi.org/10.1016/j.fct.2013.10.011

[25] Hsu, L.S., Ho, H.H., Lin, M.C., Chyau, C.C., Peng, J.S. and Wang, C.J. (2012) Mulberry Water Extracts (MWEs) Ameliorated Carbon Tetrachloride-Induced Liver Damages in Rat. Food and Chemical Toxicology, 50, 3086-3093. https://doi.org/10.1016/j.fct.2012.05.055

[26] Latief, U., Husain, H., Mukherjee, D. and Ahmad, R. (2016) Hepatoprotective Efficacy of Gallic Acid during Nitrosodiethylamine-Induced Liver Inflammation in Wistar Rats. The Journal of Basic \& Applied Zoology, 76, 31-41. https://doi.org/10.1016/j.jobaz.2016.07.002

[27] Gupta, P., Bansal, M.P. and Koul, A. (2013) Lycopene Modulates Initiation of N-Nitrosodiethylamine Induced Hepatocarcinogenesis: Studies on Chromosomal Abnormalities, Membrane Fluidity and Antioxidant Defense System. Chemico-Biological Interactions, 206, 364-374. https://doi.org/10.1016/j.cbi.2013.10.010

[28] El Mesallamy, H.O., Metwally, N.S., Soliman, M.S., Ahmed, K.A. and Abdel Moaty, M.M. (2011) The Chemopreventive Effect of Ginkgo biloba and Silybum marianum Extracts on Hepatocarcinogenesis in Rats. Cancer Cell International, 11, 38. https://doi.org/10.1186/1475-2867-11-38

[29] Vrzal, R., Illes, P. and Dvorak, Z. (2016) Transplant Drugs Affect the Expression of Phase II and Antioxidant Enzymes in Human Carcinoma Cells HepG2 But Not in 
Primary Cultures of Human Hepatocytes: In Vitro Comparative Study. Pharmacological Reports, 68, 1008-1014. https://doi.org/10.1016/j.pharep.2016.06.001

[30] Husain, H., Latief, U. and Ahmad, R. (2018) Pomegranate Action in Curbing the Incidence of Liver Injury Triggered by Diethylnitrosamine by Declining Oxidative Stress via Nrf2 and NFkappaB Regulation. Scientific Reports, 8, Article No. 8606. https://doi.org/10.1038/s41598-018-26611-1

[31] Mukherjee, D. and Ahmad, R. (2015) Dose-Dependent Effect of N'-Nitrosodiethylamine on Hepatic Architecture, RBC Rheology and Polypeptide Repertoire in Wistar Rats. Interdisciplinary Toxicology, 8, 1-7.

https://doi.org/10.1515/intox-2015-0001

\section{Appendix A. Supplementary Data}

This document file contains Supplementary Table A1.

Evaluation of the liver cancer prevention of anthocyanin extracts from mulberry (Morus alba L.) variety PR-01.

Table A1. Structural identification of the mulberry anthocyanin monomer.

\begin{tabular}{ccccc}
\hline Peak & Compound & Code & {$[\mathrm{M}-\mathrm{H}]^{+}(\mathrm{m} / \mathrm{z})$} & Fragment $(\mathrm{m} / \mathrm{z})$ \\
\hline 1 & pelargonidin 3-glucoside chloride & P3G & 433.09 & 271 \\
2 & Cyanidin-3-O-glucoside chloride & C3G & 449.08 & 287 \\
3 & Cyanidin 3-rutinoside chloride & C3R & 595.05 & 287,449 \\
\hline
\end{tabular}

